\title{
Puang as Form of Address to Maintain Harmony in Social Interaction
}

\author{
Gusnawaty \\ Faculty of Cultural Sciences, Hasanuddin University Makassar \\ gusnawaty@unhas.ac.id
}

\begin{abstract}
The greeting is a form of language behavior in social interaction that cannot be denied. However, greeting research has not been done much, especially in maintaining social relationships. This article aims to explore the use of the Puang greeting as a tool for social interaction in South Sulawesi. The data collection method is a survey of language users involved in formal and informal affairs in the Bugis-Makassar community. The survey was made by using a google form that was distributed randomly through WhatsApp Group with an age range of 17-55 years. Respondents who returned the form were 367 people. Data were analyzed using descriptive statistics with a socio-pragmatic approach. As a result, the use of Puang greetings in social interactions has experienced a shift-first, the motivation of the communicator. Second, the Puang greeting belongs to the Bugis-Makassar-speaking community and other ethnic groups in Indonesia in South Sulawesi. In conclusion, the greeting Puang is one of the unique greetings of the Bugis language to maintain harmony in social interactions both personally and communally.
\end{abstract}

Keywords: Motivation, Greeting Puang, Social Interaction, Bugis-Makassar, Indonesia

\section{INTRODUCTION}

Greeting (terms of address) is a lingual unit (morpheme, word, or phrase) commonly used in social interaction. A typical form of greeting in the social interaction of the Bugis community, one of which is the greeting Puang. This greeting is a form of respect and a marker of one's aristocratic status. This reality is in line with Leech's [1] opinion that the terms of address are an important formulaic verbal behavior well recognized in the sociolinguistic literature as they signal transactional, interpersonal and deictic ramifications in human relationships. This means that greeting as verbal behavior, signifies transactional, interpersonal and deictic consequences in human relationships. Therefore, the use or selection of greetings tends to depend on some factors such as socioeconomic status, age, gender, the relationship that exists between the interlocutor and the domain of the communicative encounter. This is categorized by Brown \& Gilman [2] into two dimensions, namely the dimension of power 'power' and the dimension of solidarity 'solidarity.'

These two dimensions become the most essential points made by researchers who investigate the nominal form of greeting. When used as a greeting, the social meaning of a word does not necessarily have a close relationship with the literal meaning of the word [3]. This fact is essential to explain how greeting plays a role because, in some languages, the form of greeting that has a degrading literal meaning serves as a form of greeting with a positive social sense, and it is also possible for the greeting to be much less complementary than would be expected from the literal sense [3]. In addition, some words can hardly be used as greetings (e.g., gas station attendant), while others appear only as adjectives (e.g., sir; Spencer \& Zwicky, [4]; (Dickey, [5]).

Research on greetings has become essential aspect in linguistic forms that are mainly related to social interactions in both the world context and the Indonesian context. In the global context, for example, research on the role of greeting forms in Hungarian society interaction by Stör [6] from Harvard University. Likewise, Farghal \& Shakir [7], Jordanian Arabic denotes kin terms and titles of address which include forms of distance and affection. The form of distance is used exclusively between strangers, while the form of affection is mainly used between friends or relatives and sometimes between strangers. Then, in the Indonesian context, the greeting is a manifestation of social stratification, which can be seen in several regional languages, such as English. There are two Balinese groups, namely the triwangsa community and the Wangsa Jaba [8], others in the Bugis language. There are three greeting patterns by Bugis speakers for their addressees, namely (1) the form of a very distant expression of respect by using a title (nobility/position) and a third-person sentence structure, (2) a respectful 
statement distanced from a title (nobility/position), and (3) a respectful statement and an untitled greeting. They are only recognized through honorific enclitics - $k i$ used by speakers [9], and Bugis greetings in the context of gender pragmatics [10]. All these studies show that greeting is a phenomenon of linguistic form in every language which is interesting to be investigated to find its role in the social interaction of a language user community.

However, based on a review of the research on greetings, especially in Bugis, it appears that the greeting Puang has not been studied specifically. As a result, the younger generation does not get proportional information about the use of greetings, especially the Puang greeting. In addition, from the sociolinguistic and pragmatic aspect, this greeting is very interesting and important, especially in the current era of millennial interaction. Therefore, this study examines the greeting Puang specifically in four ways. (4) aspects, namely aspects of users, frequency, context, and aspects of motivation. The findings from these four aspects of greeting Puang will make a scientific contribution in uncovering non-linguistic factors that influence language use, in addition to the linguistic factors themselves. In addition, this study can clarify the relationship between language and society, namely the relationship between language and the social level of society, especially the social level in terms of nobility, not in terms of education or the economy.

\section{METHODOLOGY}

This research is sociolinguistic research with a survey method of language users who are involved in formal and informal affairs in the Bugis-Makassar community. The research instrument used a google form that was distributed randomly through WhatsApp Group with an age range of 17-55 years. The questionnaire in the form of a google form contains nine questions related to aspects of the user, frequency, situation, and motivation, which are the background for the use of greetings Puang. Respondents who returned the form were 367 people. Data analysis using quantitative descriptive using four (4) theoretical perspectives or concepts, namely Indexicality, Language and Identity Theory, Language Attitude and Language Ideological Theory, and Communication Accommodation Theory.

\section{ANALYSIS}

The presentation of the research analysis is divided into two (2) parts: first, the presentation of the graphs of the research results, and second, the interpretation of the analysis of the research results in four theoretical perspectives or concepts.

\subsection{Graph of the research Results}

\section{User Aspect User}

aspects are divided into two (2) categories, namely, the user's ethnic background category is shown in Graph 1a, and the user's age category is shown in Graph 1b.
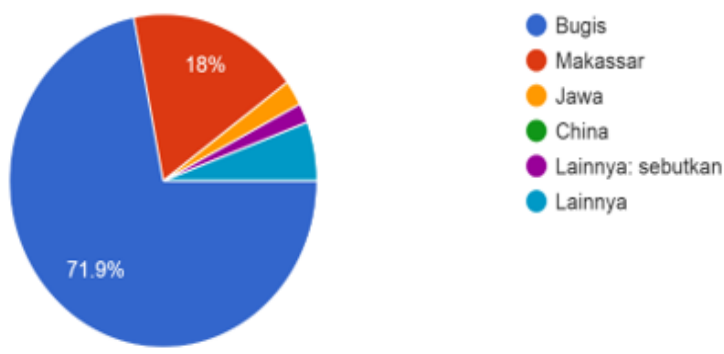

Graph 1a: Percentage of Tribal Background Users of the Puang Address

Graph 1a above illustrates that Bugis greetings, especially the greeting Puang/Pung, are also used by speakers of other languages, such as Makassar, Javanese, Chinese, and other ethnic groups. This is due to the existence of a principle in the Bugis language called mappasitinaja (property, fairness) and mappalaiseng (discrimination). To realize the principle of mappalaiseng, a Bugis language speaker needs to know or understand the strata and status of each party so that words or forms of greeting that are appropriate (appropriate) are spoken to the interlocutor [11]. The concept sitinaja is in line with the concept of communication strategy [12]. That for communication to be achieved, the communicant actors need to use certain strategies in communicating. The strategy in question is in the form of choices of polite or appropriate words because otherwise, the communication contact will be broken.

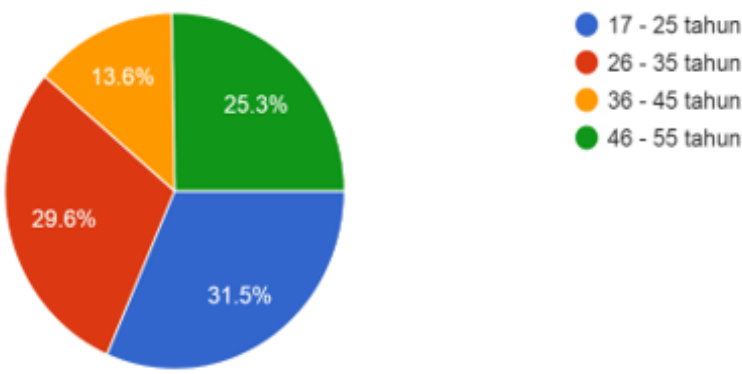

Graph 1b: Age Percentage of Address Users Puang

Graph 1b shows that the users of greeting Puang highest number of, sequentially, is the first largest user, with an age range of 17-25 years as many as 116 people or $31.5 \%$. The second rank, the age range of $26-35$ years, as many as 109 people or $29.6 \%$. The third rank, age range 46-55 years as many as 93 respondents. Lastly, are users with age ranges. $25.3 \%$ 36-45 years as many as $13.6 \%$ or 49 people. 


\section{The aspect of Frequency}

The frequency of using greetings Puang from 367 respondents is shown in Graph 2 below.

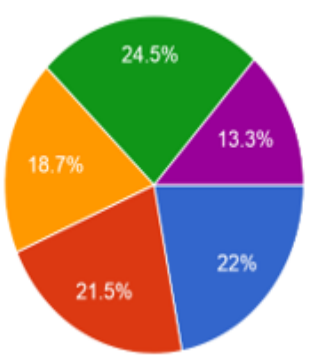

$$
\begin{aligned}
& \text { Sangat Jarang } \\
& \text { Jarang } \\
& \text { Cukup } \\
& \text { Sering } \\
& \text { Sangat Sering }
\end{aligned}
$$

Graph 2: Frequency of Using the Puang Address in Social Interaction

Graph 2 illustrates the reality that the use of the greeting Puang in social interaction has begun to be rare and even rarely used by speakers. There are $41.4 \%$ speakers or 160 people who rarely and very rarely use it. Only $37.8 \%$ of speakers use it frequently and very often. While those who sometimes use only $18.7 \%$ of speakers.

3. Context Aspect

The current situation of using the address Puang is illustrated in Graph 3 below.
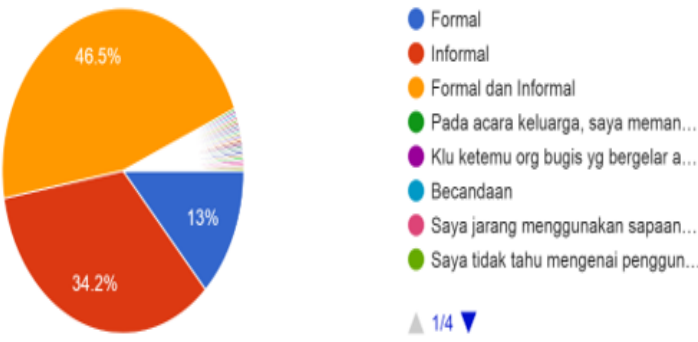

Graph 3: Situation of the Use of Address Puang in Social Interaction

Graph 3 above shows that the situation or context of the use of greeting Puang is still dominant in informal situations, namely $46.5 \%$. However, there are $34.2 \%$ of speakers use this greeting in both formal and informal situations. Only $13 \%$ of speakers use it in a formal context. The results of this study show that only $6 \%$ of speakers use the Puang greeting in a formal context in government offices, as illustrated in Graph 4 below.

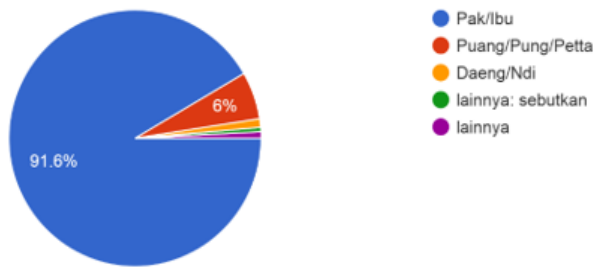

Graph 4: Puang Greetings in Formal Situations in Government Agencies
Graph 4 shows that the use of Puang greetings in formal situations in government agencies is only $6 \%$.

\section{Aspects of Motivation The motivation}

Referred to in this study is something that is the reason and/or purpose of the speaker when choosing to use the greeting Puang. This can be seen from three (2) things, namely goals including personal non-economic goals (Graph 5), personal economic goals (Graph 6), and social goals (Graphs 7a and 7b).

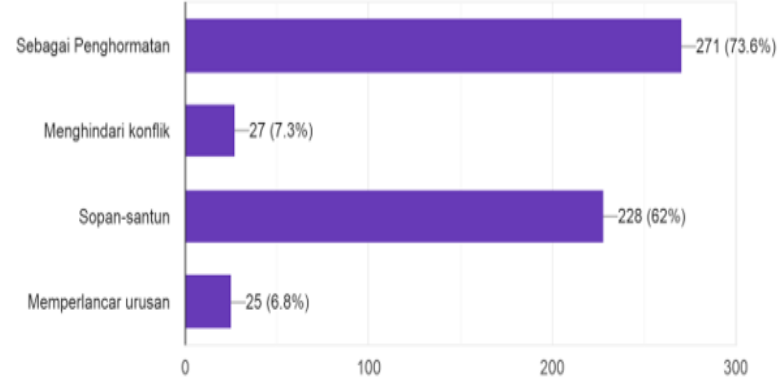

Graph 5: Non-Economic Personal Motivation in Using the Puang Address

Graph 5 illustrates that $73.6 \%$ or 271 speakers use the Puang greeting intending to respect the speech partner and $62 \%$ for politeness.

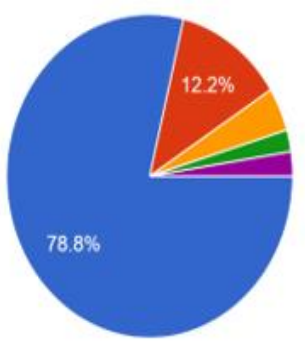

- Pak/lbu

Puang/Pung/Petta Daeng/Ndi lainnya:sebutkan lainnya

Graph 6: The Use of greetings Puang in Offering Goods/Services

Graph 6 above informs that the use of Puang greetings for economic motivation is relatively small, only $12.2 \%$. This shows that someone who has economic motivation assumes that the greeting Puang does not have the value of emotional encouragement from prospective buyers or service recipients. 


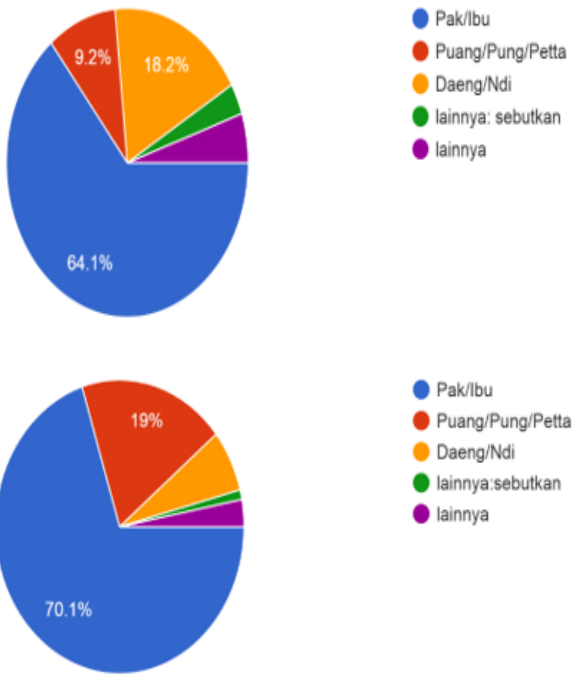

Graph 7a: Social Motivation, Reconciling Graph 7b: Social Motivation, Receiving / Visiting

Graph 7a illustrates that when reconciling a dispute or dispute, the choice of greeting Puang is speakers only 9.2\%. Meanwhile, when visiting or receiving guests, there are $19 \%$ of speakers use the greeting Puang.

\section{A. Interpretation of Analysis of Research Results}

When people interact, the nature of their interpersonal relationships is manifested in various ways: by the distance, they stand from each other, their posture, their facial expressions, how much they look at each other, and so on. It is also implied in the language they use. Relationships are also manifested in lexical choices, especially in the terms people use to greet each other. Two lexical options reflecting the relationship between language use and interpersonal relationships will be considered, namely the mode of greeting and politeness [13].

The analysis interpretation of the four (4) aspects of the use of the address Puang in this study is presented sequentially, starting from theory indexicality, Language and Identity Theory, Language Attitude and Language Ideological Theory, and Communication Accommodation Theory.

\section{The use of Puang's address in the perspective of Indexicality}

Linguistic signs have two types of meaning: referential one and one that is indexical. The latter meaning is context-dependent and "brings to consciousness contextually relevant meanings, including the situation itself. This rule is illustrated in the form of the greeting Puang in the social interaction of the Bugis community. Indexicality, as defined by Bucholtz \& Hall [16] is "the semiotic process of juxtaposition, whereby one entity or event points to another". Furthermore, Ochs [17] shows that greeting does not only contribute to the denotational or referential meaning of a sentence but also indexes its communicative context (e.g. the speaker's social status or social relationship between the speaker and the recipient). By their references and also by their social Indexicality. Relation 36-55

To the speaker's social status or relationship, Graph $1 \mathrm{~b}$ above which illustrates that the age range of years is only $38.9 \%$ who use the greeting Puang. While the age range of speakers is 17-35 years, namely as much as $61.1 \%$ use the greeting Puang in their social interactions. This reality is in line with the opinion of Krauss \& Chiu [13] which states that attitude changes can be characterized by speech characteristics, such as changes in lexical use and changes in attitudes about the effect of persuasive messages on the recipient. Furthermore, using or not using the greeting Puang is also an option. The two age groups, of course, want to show 'humanity' and their dignity [14].

In addition, the form of greeting Puang, as a form of respect, has a basic meaning known as a direct index. According to Brown [15] "this direct indexic meaning is enriched into a specific social meaning when used in context. Indexical meanings directly interact with the context and are mediated by linguistic and nonlinguistic features that occur together to produce situational meanings or indirect indexes' (p. 43). Therefore, indexical signs can communicate a variety of social meanings because some of their meanings depend on the context.

Furthermore, Indexicality can also help us understand the effects of speech. The results in Graph 6, Graph 7a, and Graph 7b illustrate this. The speaker chooses the greeting Puang to get the effect according to the speaker's wishes. The analysis in Figure 6 illustrates that there is $12.2 \%$ of the use of greetings Puang in offering goods or services. Likewise, Graph 7a shows a $9.2 \%$ result, while Graph $7 b$ shows a $19 \%$ result. These results indicate that greeting Puang today has been understood and accepted as a greeting that creates intimacy or closeness as well as respect. Of course, this finding gives a different meaning from the previous meaning of this greeting. At the same time, the greeting plan indicates the distance between the speaker and the addressee.

\section{Communication Accommodation Theory}

The use of language in interaction requires more than just exchanging information about thoughts and factual matters between one person to another; it is an important process by which relationships between people are described and negotiated. Participating in conversation, people consciously or unconsciously show their identity, their belonging to a particular culture or group, and also their tendency to be near or far from other people. This is the basis of the theory of communication accommodation.

This theory states that people use communication to manage their social relationships and that they show affiliation or disaffiliation with others not only through 
what they say but also how they say it. The analysis of the research results in Graph 2 regarding the frequency of using the greeting Puang is an example of how to manage social relationships.

Graph 2 illustrates the reality that the use of greetings Puang in social interactions has begun to be rarely even used by speakers. There are $41.4 \%$ speakers or 160 people who rarely and very rarely use it. Only $37.8 \%$ of speakers use it frequently and very often. While those who sometimes use only $18.7 \%$ of speakers.

\section{Language and social identity}

The notion of language, in part, and especially language in conflict, lies in the complexity of the relationship between self-identification, group cohesion, and worldview Chriost, [18]. Thus, the acquisition of a language is not only the internalization of a linguistic code, but also requires the learning of status and roles, appropriate social effects, and (eventually) a worldview. Language provides the foundation of a shared cultural identity and a means for the reproduction of social differences.

The social difference in this study is manifested in one of the greetings in the Bugis community, the Puang. Graph 3 above shows that social differences can be influenced by context. The context of the use of the greeting Puang dominant in informal situations is $46.5 \%$. This reality reinforces the notion that the nuances of aristocracy still have a strong influence in the everyday context of Bugis society. Even for formal contexts, there are $13 \%$ of speakers who still address this Puang. Especially in government agencies, there are $6 \%$ of speakers who use it. Then, there are $34.2 \%$ of speakers use this greeting in both formal and informal situations. This finding shows that social differences in society can occur in specific contexts.

This is in line with the fundamental theory of language. This theory states that for speech acts is the idea that different locutions can have the same illocutionary (and perlocutionary) power. Any utterance can be "Very" meaningful by taking into account the various factors that limit use in certain situations. These factors include social norms governing use in that situation, aspects of the speaker-receiver relationship, information the receiver has and does not have, etc. [19]; [20]; [21].

\section{Language attitudes and language ideologies}

The concept aims to reveal something about the relationship between speech and the material conditions of possibility when the conditions of possibility are viewed in the light of specific forces which are central to the reproduction (or also, for some theories, the contestation) of a whole-forms of social life. An example is the analysis of the results of this study in Graphs 5, 6, and 7, which show the motivation of speakers in the selection and use of greetings Puang. The explanation referred to in this study is something that is the reason and/or purpose of the speaker when choosing to use the greeting Puang.

Graph 5 illustrates the speaker's motivation is to pay respect and show personal politeness. This finding is in line with the concept of social interaction that exists in Bugis society, namely adat. In it, some rules regulate human life [22]. The rules are in the form of paseng 'messages and/or advice', namely sadda mappabbati there is 'the sound of manifesting kat'; there is mappabbati gau 'the word manifests the deed'; and gau mappabbati or 'the act of creating a human being' [23]. That there are or words that come out of the mouth that can hurt and cause conflict. So, words are the origin of actions that must show the degree of humanity [9]. Furthermore, Bugis people also have expressions that read 'ada emmi ni yasengki tau' (only (from) words that show we are human). Therefore, the choice of words in speaking is essential to show the 'humanity or dignity of a person [14]. So, it can be said that people in South Sulawesi still had a good attitude and ideology in the Bugis language in the middle of the millennium era. Furthermore, this result also illustrates the character of politeness and courtesy as the essential character of a person or society that is still firmly held. The findings there are $73.6 \%$ or 271 speakers use the greeting Puang to respect the speech partner and $62 \%$ with the aim of politeness.

Language attitudes and ideologies can also be identified in the economic and social motivations of speakers. As the results in Graph 6 and Graph 7a and Graph $7 \mathrm{~b}$. The findings in the three graphs show that the use of greetings for economic motivation is relatively small, only $12.2 \%$. In the perspective of language attitude theory and language, ideology has a positive meaning. That is, speakers still place the greeting Puang in its original frame, namely as a greeting for respect and showing nobility. This is in line with the opinion of Bruner, Jerome, [24] that "The symbolic system used by individuals in constructing meaning is a system that already exists, already 'exists,' deeply embedded in culture and language.

\section{CONCLUSION}

Harmonization in social interaction can be created by one of them through the election and the use of greeting Puang. This conclusion is based on the results of an analysis of four (4) aspects, namely aspects of users, frequency, context, and aspects of motivation using four (4) theories or concepts. The four theories are indexicality theory, Communication Accommodation Theory (Communication) Accommodation Theory), Language and social identity, and Language attitudes and language ideologies. The description of the interpretation of the philosophy of the four theories finds a non-language value, namely the harmony of the four aspects of greeting Puang.

This study also strengthens the four theories mentioned above regarding the relationship between 
language and society and language and level $\mathrm{n}$ social community. Social level in terms of nobility, the formal hierarchical utterance in this paper is defined as mappalaiseng in Bugis language, which means 'distinction.' That is, in speech, there are differences in the social structure [9].

\section{REFERENCES}

[1] Leech, G. (1999). The Distribution and Function of Vocatives in American and British English Conversation. In H. Hasselgared \& S. Oksefjell (Eds.), Out of Corpora: Studies in Honor of Stig Johanson (pp. 107-118). Amsterdam: Rodopi.

[2] Brown, \& Gilman. (1970). The Pronouns of Power and Solidarity. In JA Fishman (Ed.), Readings in Sociology of Language. Paris: Mouton.

[3] Braun, F. (1988). Terms of Address: Problem of Patterns and Usage in Various Languages and Cultures. (JA Fishman, Ed.). Berlin, New York, Amsterdam: Mouton de Gruyter.

[4] Spencer, A., \& Zwicky, AM (2001). The Handbook of Morphology (Blackwell Handbooks in Linguistics). New York: Blackwell Publishing.

[5] Dickey, E. (1997). Forms of address and terms of reference. Journal of Linguistics, 33(2), 255-274.

[6] Stör. (1982). Terms of address and Hungarian society. Language Sciences, 4(1), 55-69.

[7] Farghal, M., \& Shakir, A. (1994). Kin Terms and Titles of Address as Relational Social Honorifics in Jordanian Arabic. Anthropological Linguistics, 36(2), 240-253.

[8] Suwija, IN (2018). Balinese greeting system according to kinship. Sociohumanities-Journal of Social Sciences And Humanities, 20(2), 115-121.

[9] Gusnawaty, G. (2011). Politeness Behavior in Bugis: Sociopragmatic Analysis. Unhas Postgraduate Program, Makassar.

[10] Agus, N. (2014). Bugis Language Address Forms in the Context of Gender Pragmatics. Sawerigading, 20(1), 1-13.

[11] Gusnawaty, G. (2013). Greeting Patterns in Bugis: The Ritual of Harmony that Glues together. In the International Congress of the Indonesian Linguistic Society (KIMLI) (pp. 1-10).

[12] Brown, P., \& Levinson, SC (1987). Politeness: Some Universals in Language Usage. Cambridge: Cambridge University Press.

[13] Krauss, RM, \& Chiu, CY (2014). Language and social behavior. In DGS Fiske \& G. Lindsey (Eds.), Handbook of Social Psychology (Fourth, pp. 41-88). Boston: McGraw-Hill.

[14] Dervish, M. (1992). Speech Level in Bugis Language. Ujung Pandang: Hasanuddin
University Research Institute.

[15] Brown, P. (2015). Politeness and Language Studies in its History, Theory, and Practice. (RJ Watts, S. Ide, \& K. Ehlich, Eds.) (Second). Berlin New York: Mouton de Gruyter.

[16] Bucholtz, M., \& Hall, K. (2004). Languages and Identity. In A. Duranti (Ed.), A Companion to Linguistic Anthropology (pp. 369-394). United Kingdom: Blackwell Publishing. Retrieved from https://escholarship.org/uc/item/7198t0cr

[17] Ochs, E. (1990). Indexicality and Socialization. In JW Stigler, RA Schweder, \& G. Herdt (Eds.), Cultural Psychology: Essays on Comparative Human Development (pp. 287-308). California, USA: Cambridge University Press.

[18] Chriost, DMG (2003). Language, Identity, and Conflict. Arabic in Israel. London and New York: Routledge Taylor \& Francis Group.

[19] Austin, JL (1962). How To Do Things With Words. Great Britain: Oxford University Press.

[20] Searle, JR (1969). Speech Acts An Essay in The Philosophy of Language. New York: Cambridge University Press

[21] Searle, JR, Kiefer, F., \& Bierwisch, M. (2013). Speech act theory and pragmatics. Research Methods in Critical Security Studies: An Introduction. Holland: Reided Publishing Company.

[22] Yusuf, M. (2013). Corruption and Public Integrity: Perspective of Bugis Cultural Values and the Qur'an. Jurnal Pilar, 2, 79-99.

[23] Mattulada, H. (1975). Latoa. An Analytical Painting on Anthropology-Political Bugis People. Jakarta: Unpublished.

[24] Bruner, Jerome, S. (1990). Acts of Meaning. USA: The President and Fellows of Harvard College. 